\title{
Original Article (short paper) \\ The effects of an after-school intervention program on physical activity level, sedentary time, and cardiovascular risk factors in adolescents
}

\author{
Roseane de Fátima Guimarães ${ }^{1,2 *}$, Michael Pereira da Silva ${ }^{3}$, Mariana Contiero San Martini ${ }^{1}$, Gil Guerra-Júnior ${ }^{1}$, \\ Ezequiel Moreira Gonçalves ${ }^{1}$ \\ ${ }^{1}$ Universidade Estadual de Campinas, UNICAMP, Campinas, SP, Brazil; ${ }^{2}$ Centro Universitário Salesiano de São \\ Paulo, UNISAL, Campinas, SP, Brazil; ${ }^{3}$ Universidade Federal do Paraná, UFPR, Curitiba, PR, Brazil.
}

\begin{abstract}
Aim: To ascertain the effects of an after-school intervention on physical activity levels and cardiovascular risk factors in adolescents from Campinas, Brazil. Methods: This was an intervention study with 71 adolescents that was carried out in two schools, randomly assigned to a control group (CG:n=45) or an intervention group (IG:n=26). We performed evaluations of body composition, sexual maturation, blood pressure, level of physical activity, sedentary time (ST), and eating habits, as well as biochemical variables by a portable analyzer. The IG participated in two weekly sessions of physical activities and controlled physical exercises for 14 weeks. The sessions lasted 60', and were divided into warm-up (5-10'), main part (40-50'), and recovery (5-10'). Results: $30.8 \%$ of the IG and $24.4 \%$ of the CG were classified as overweight/obese. Additionally, the IG showed significantly lower ST (total: $p=0.037$; daily: $p=0.009$ ) after the intervention, as well as in the post-period (total ST: $p=0.043$; daily ST: $p=0.007$ ). The IG showed a reduction in glycemia $(p=0.025)$. Conclusion: The intervention program generated positive changes in glycemia levels and ST. These results suggest that interventions involving physical exercise should be promoted in the school environment, as physical activity is an important component of a healthy lifestyle.
\end{abstract}

Keywords: motor activity, body composition, risk factors, adolescents, clinical trial

\section{Introduction}

Adolescence is the ideal life stage to promote good living habits and the prevention of cardiovascular risk factors, since one's lifestyle in this stage tends to persist into adulthood ${ }^{1}$. Interventions in the school setting may be a promising strategy to promote health through recreational and competitive physical activity, as well as nutrition education, since adolescents spend most of their time in this environment.

Over the past few decades, there has been a substantial increase in overweight and obesity among adults throughout the world ${ }^{2,3}$, and in Latin America it is estimated that 16 to 21 million adolescents are overweight or obese ${ }^{4}$. Brazil, as a developing country, has been facing the same problem as developed countries, showing a combined prevalence of overweight and obesity of approximately $30 \%$ in adolescents ${ }^{4}$. Overweight/obesity has negative effects on health throughout life, and physical activity (PA) is widely recognized as a preventive measure among adolescents ${ }^{5-7}$. It is also considered important to reduce cardiovascular risk factors, such as obesity combined with elevated blood pressure and glucose levels, and lipid abnormalities ${ }^{1,8}$.

In Brazil, few school interventions on physical/nutritional activities have been performed to reduce health risk factors ${ }^{9}$. Some results should be highlighted, such as the significant body fat reduction observed in all studies ${ }^{10-15}$, positive changes in blood parameters, and improvement in physical abilities and blood pressure.

Other foreign studies have shown that regular PA and the reduction of sedentary time (especially screen time) significantly decrease the incidence of overweight and obesity in adolescents ${ }^{5,6,16,17}$. Despite these benefits being widely known, PA levels have decreased dramatically in adolescents, especially among females ${ }^{18}$. Thus, there is an urgent need for physical activity and nutrition education interventions aimed at promoting healthier behaviors and favoring improvements in health risk factors in adolescents. School and community-based intervention is an important and promising strategy to minimize this real threat to public health and maximize the success of morbidity prevention in adolescence, given that adolescents attend school for a significant part of the day $y^{1,19,20}$.

The objective of this study was to ascertain the effects of an after-school intervention on physical activity levels and cardiovascular risk factors in adolescents from Campinas, Brazil.

\section{Methods}

\section{Study design and sample selection}

We conducted an intervention study from August to November 2015 in two intentionally selected public schools in 
Campinas, São Paulo, Brazil. Three hundred students enrolled in secondary education in the morning period at each school were invited to participate in the study. The inclusion criteria were as follows: the submission of an informed consent form signed by a parent/legal guardian, aging 19 years or younger, no physical limitation that prevents performance of the proposed activities, no chronic use of anti-hypertensive drugs, and no known condition that could affect any of the variables analyzed in the study. The criteria for choosing the schools were their proximity to the place where the interventions were conducted, and their similar neighborhoods, which contributed to avoiding disparities between the adolescents' socioeconomic statuses.
Both schools were randomly assigned to a control group (CG) or intervention group (IG). In the beginning of the study, 114 adolescents (CG: $n=65$ and IG: $n=45$ ) met the inclusion criteria. At the end of the post-intervention evaluations, 71 adolescents (CG: $\mathrm{n}=45$ and $\mathrm{IG}: \mathrm{n}=26$ ) with valid data remained, as shown in Figure 1, which is based on the CONSORT 2010 flow diagram ${ }^{21}$.

This study was approved by the Research Ethics Committee of the Faculty of Medical Sciences of the State University of Campinas (Term of approval No. 887.055/2014, CAAE: 35583014.9.0000.5404).

Figure 1. Flowchart of the selection of the control and the intervention groups (based on CONSORT 2010 Flow Diagram).

Two secondary schools invited to participate in the study $(\mathrm{n}=300$ students invited)

Excluded $(\mathrm{n}=186)$ :

Did not meet inclusion criteria and/or refused to participate
Eligible students with consent form signed by legal guardian

$$
(\mathrm{n}=114)
$$

\section{Schools ramdomly divided into Control Group (CG) and Intervention Group}

(IG)

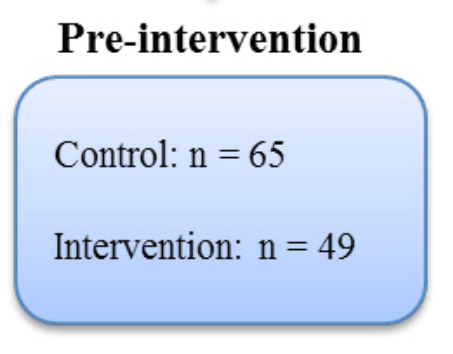

\section{Post-intervention}

Control: $\mathrm{n}=45$

Intervention: $\mathrm{n}=26$
Reasons for the losses: CG: Refusal to participate $(\mathrm{n}=10)$; Noshows at the school on the evaluation day $(\mathrm{n}=15)$.

IG: 5 or more absences in the meetings $(\mathrm{n}=20)$; Quitting/Refusal to participate $(n=3)$.

\section{Instruments and procedures}

\section{Sexual maturation}

The pubertal status of both groups was determined using the equations developed and validated by Mirwald, Baxter-Jones, Bailey, Beunen ${ }^{22}$ to predict years from peak height velocity (PHV) based on the single measurement of several anthropometric parameters. These sex-specific predictive equations incorporate the interactions between height, weight, sitting height, and limb length to determine a maturity offset that is added to chronological age to obtain the PHV. The ability of these equations to predict actual PHV have been reported as $r 2=0.890$ and $r 2=0.891$ for boys and girls, respectively ${ }^{22}$. 


\section{Physical activity levels}

The International Physical Activity Questionnaire (IPAQ) (short version) assessed the adolescents' physical activity ${ }^{23}$. The PA level for each intensity (light, moderate, and vigorous) was calculated in minutes per week.

\section{Sedentary time}

The Adolescent Sedentary Activity Questionnaire (ASAQ) (Brazilian version) ${ }^{24}$ evaluated the time spent on sedentary activities. It asks adolescents to recall the time (in hours and minutes) they usually spend (in a typical week) on different sedentary activities, on weekdays and weekends. The amount of time spent on each sedentary activity was calculated in minutes, and total time was calculated in the same manner - as the sum of all sedentary activities on weekdays and weekends, daily time spent, and electronic time spent. The adolescents were classified as having excessive sedentary time if they had more than two hours per day in the electronic aspect ${ }^{25}$.

\section{Cardiovascular risk factors}

\section{Body composition}

All anthropometric procedures were performed by a certified professional following the protocols recommended by the International Society for Advancement in Kinanthropometry ${ }^{26}$. Body mass index (BMI) was calculated through the quotient of weight (kg)/height (m) squared, and subjects were classified as overweight or obese based on the International Obesity Task Force $^{27}$ cut-off.

To determine body composition, subjects underwent bioelectric impedance analysis (BIA) using a tetrapolar unifrequency $(50 \mathrm{kHz}$ ) device (Quantum II, RJL Systems, Detroit, EUA). This BIA device provides the values of resistance (R) and reactance $(\mathrm{Xc})$ in ohms $(\Omega)$. The protocol for BIA was the previous preparation to standardize hydration, following the recommendations of $\mathrm{Kyle}^{28}$. The equation used to determine fat free mass (FFM, kg) was proposed by Houtkooper, Going, Lohman, Roche, Van Loan ${ }^{29}$. After the determination of FFM, we determined fatty mass in kilograms (FM = body weight - FFM), and the percentage of body fat: $\mathrm{BF} \%=(\mathrm{FM} \times 100) /$ weight.

\section{Eating habits}

A simplified questionnaire of eating frequency assessed the consumption of fat-rich foods related to increased risk of coronary disease ${ }^{30}$. It provides a numeric score according to the reported frequency of consumption over the 30 days prior to data collection. Scores higher than 100 indicate an altered eating habits' condition.

\section{Biochemical variables}

We collected the blood values for total cholesterol, triglycerides, and glucose through the analysis of a drop of blood taken from participants' fingertips using a sterile and disposable lancet, after a fast of 12 hours. To obtain the values, we used a portable biochemical analyzer (Roche's Accutrend Plus); the measurement principle was based on the reflectance photometry method. The adolescents' results were classified in accordance to the reference values of the Brazilian Society of Cardiology and the American Diabetes Association ${ }^{31,32}$.

\section{Blood pressure}

Blood pressure was measured using the auscultatory method, following the parameters established in the $4^{\text {th }}$ report by the National High Blood Pressure Education Program ${ }^{33}$. Values above $120 / 80 \mathrm{mmHg}$ were considered elevated ${ }^{33}$. Mean blood pressure (MBP) was calculated according to the following formula: MBP $=[$ systolic blood pressure $+(2 \times$ diastolic blood pressure $)] / 3$.

\section{Intervention program}

The IG adolescents participated in two weekly sessions of recreational physical activities and controlled physical exercises for a period of 14 weeks. The sessions lasted 60 minutes, and were divided into three parts: warm-up (5-10 minutes), main part (40-50 minutes), and recovery (5-10 minutes). All sessions were performed in the afternoon, in the sport areas of Centro Universitário Salesiano de São Paulo - Liceu Salesiano, located about $4 \mathrm{~km}$ from the IG's school. The researcher (a physical education teacher) was in charge of planning and carrying out the intervention sessions.

The adolescents of the IG received weekly text messages on their respective cell phones for attendance control of the intervention program. It was established that they should attend at least $80 \%$ of the scheduled sessions, with the possibility of being absent from a maximum of five meetings throughout the 14 weeks. Students who exceeded the maximum number of allowed absences were excluded from the study. In addition, IG participants attended monthly instructional meetings hosted by a nutrition specialist. During these meetings, the adolescents received information about good eating habits and their benefits to adolescents' health. PA intervention and instructional meetings were not performed with adolescents in the CG, who continued their regular school routine.

All measurements were taken on the premises of the participating schools, in the morning, on two occasions: at the beginning and at the end of the second semester of 2015, for both groups (IG and CG), as shown in Figure 2. 
Figure 2. Information about the intervention program.

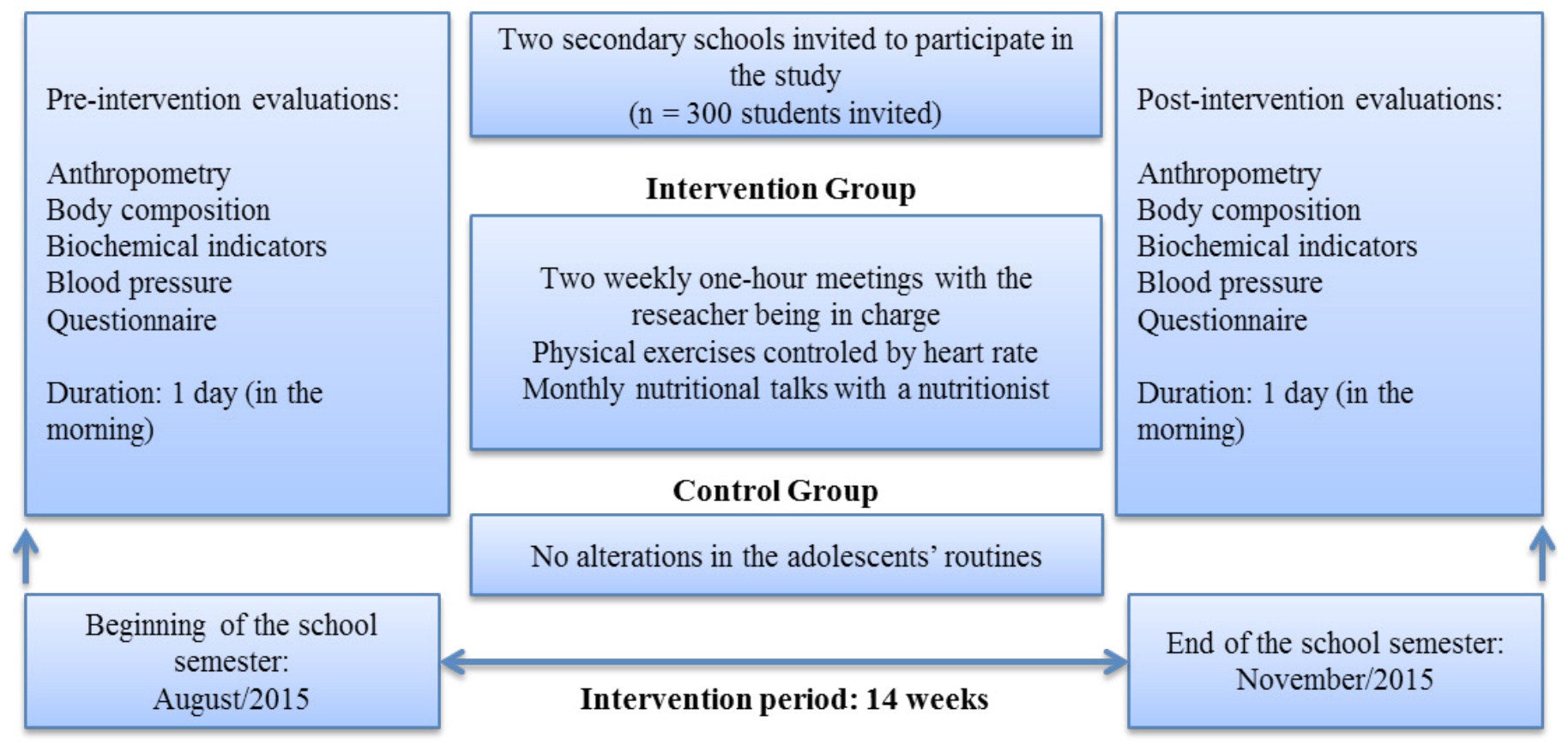

*Questionnaire: Personal information, socioeconomic level, physical activity, eating habits and sedentary behavior.

\section{Statistical analyses}

We performed a Shapiro-Wilk normality test and observed that some of the data did not follow a normal distribution, even after attempting several transformations (logarithmic, quadratic, cubic, etc.). We used a chi-square test to compare the categorical variables of gender and sexual maturation. Descriptive statistics, medians, and minimum and maximum values were used to characterize the sample. When it was applicable, we used the Student's t-test as well as the Mann-Whitney U test to compare inter-group data. ANCOVA was used to compare pre- and postintervention periods between groups, considering age and $\mathrm{PHV}$ as covariates. A Bonferroni post-hoc test was used to identify eventual differences. All analyses were performed using SPSS (version 17.0, Chicago: SPSS Inc.) statistics software, adopting the significance level of $p<0.05$.

\section{Results}

No significant association was found between the proportion of sexes and groups (girls, 85.7\% IG and 64.6\% CG; boys, $14.3 \%$ IG and $35.4 \% \mathrm{CG}$ ) in the post-intervention period; therefore, female and male subjects were grouped together for analysis. Using BMI cut-offs, the majority of adolescents were classified as eutrophic (69.2\% and 75.6\%, IG and CG, respectively) and $30.8 \%$ (IG) and $24.4 \%$ (CG) as overweight/obese. We did not find alterations in nutritional status in any of the groups when comparing pre- and post-intervention data.

Anthropometric characteristics and body composition data are presented in Table 1. The CG's age and age of PHV were significantly higher than that of the IG $(p<0.01)$. Both groups were homogeneous at baseline and there were no significant differences in anthropometric or body composition variables in the pre-intervention period.

The analysis of covariance of the intervention's effectiveness on the dependent variables, adjusted by age and PHV, showed that total ST was significantly lower in the IG $(p=0.037)$ after the 14-week intervention, as well as when comparing groups in the post-period $(p=0.043)$. We also observed a reduction in daily ST in the post-period in the IG $(p=0.009)$, and when comparing groups in the post-period $(p=0.007)$.

Table 3 shows the significant glycemia reduction observed in the IG between pre- and post-intervention periods ( $p=0.025)$, as well as the reduction of FFM $(p=0.03)$ and increase of mean $\mathrm{BP}$ in the IG $(p=0.004)$.

As demonstrated in Figure 3, there was a high rate of adolescents with altered eating habits and lipid profiles, in both periods. After the 14-week study, we observed a significant increase in the proportion of subjects with elevated cholesterol $(p<0.01)$ in the CG, and also a reduction in the proportion of adolescents classified as altered in the eating habits in the IG. The CG presented a significant increase in PHV between preand post-periods $(p<0.05)$. 
Table 1. Characteristics of CG and IG pre-intervention.

\begin{tabular}{|c|c|c|c|c|}
\hline & & GI $(n=26)$ & GC $(n=45)$ & $t$ \\
\hline Age (years) & Pre- & $16.0 \pm 0.9$ & $17.1 \pm 0.7$ & $<0.001$ \\
\hline PHV (years) & Pre- & $2.6 \pm 0.9$ & $3.2 \pm 0.7$ & 0.002 \\
\hline Weight (kg) & Pre- & $62.7(47.3-102.1)$ & $58.8(44.4-101.7)$ & 0.267 \\
\hline Height (cm) & Pre- & $163.3 \pm 8.3$ & $165.7 \pm 9.1$ & 0.265 \\
\hline BMI $\left(\mathrm{kg} / \mathrm{m}^{2}\right)$ & Pre- & $23.8(19.2-32.3)$ & $21.9(17.2-50.0)$ & 0.152 \\
\hline$\% \mathrm{FM}$ & Pre- & $30.5 \pm 7.6$ & $27.5 \pm 8.1$ & 0.123 \\
\hline FFM (kg) & Pre- & $45.3 \pm 7.6$ & $43.5(28.6-68.4)$ & 0.734 \\
\hline
\end{tabular}

Data presented in Mean \pm Standard Deviation or Median (Minimum-Maximum). PHV: Age at Peak of Height Velocity; BMI: Body mass index; \%FM: Fat mass percentage; FFM: Fat-free mass.

Table 2. Physical activity level by intensity, sedentary time and eating habits in the pre- and post-intervention periods.

IG

\begin{tabular}{|c|c|c|c|c|c|c|c|c|}
\hline & & Mean & SE & Mean & SE & Effect & $F$ & p-value \\
\hline & Pre- & 5652.1 & 241.4 & 6045.9 & 174.8 & Group & 3.67 & 0.060 \\
\hline \multirow[t]{3}{*}{ Total ST (min/week) } & Post- & $5641.0^{\mathrm{b}}$ & 244.7 & $6333.7^{b}$ & 177.2 & Time & 0.00 & 0.950 \\
\hline & & $\mathrm{p}=0.037$ & & $\mathrm{p}=0.043$ & & Interaction & 0.91 & 0.345 \\
\hline & Pre- & 2182.6 & 245.5 & 2162.9 & 177.7 & Group & 0.00 & 0.978 \\
\hline \multirow[t]{3}{*}{ ST electronic (min/week) } & Post- & 2300.7 & 219.7 & 2336.5 & 159.1 & Time & 0.20 & 0.654 \\
\hline & & & & & & Interaction & 0.05 & 0.819 \\
\hline & Pre- & $1589.22^{\mathrm{a}}$ & 76.4 & 1697.16 & 55.3 & Group & 4.67 & 0.034 \\
\hline \multirow[t]{3}{*}{ ST (min/day) } & Post- & $1556.0^{\mathrm{a}, \mathrm{b}}$ & 73.7 & $1831.67^{\mathrm{b}}$ & 53.3 & Time & 0.417 & 0.521 \\
\hline & & $\mathrm{p}=0.009$ & & $\mathrm{p}=0.007$ & & Interaction & 3.32 & 0.073 \\
\hline & Pre- & 312.2 & 77.0 & 257.5 & 55.7 & Group & 0.85 & 0.358 \\
\hline \multirow[t]{3}{*}{ MPA (min/week) } & Post- & 313.2 & 57.7 & 240.2 & 41.8 & Time & 1.69 & 0.198 \\
\hline & & & & & & Interaction & 0.24 & 0.877 \\
\hline & Pre- & 119.0 & 56.7 & 185.3 & 41.1 & Group & 0.39 & 0.534 \\
\hline \multirow[t]{3}{*}{ VPA (min/week) } & Post- & 175.6 & 46.9 & 176.4 & 33.9 & Time & 0.13 & 0.717 \\
\hline & & & & & & Interaction & 0.55 & 0.460 \\
\hline & Pre- & 431.2 & 96.9 & 442.7 & 70.2 & Group & 0.09 & 0.760 \\
\hline \multirow[t]{2}{*}{ MVPA (min/week) } & Post- & 488.9 & 88.7 & 416.6 & 64.2 & Time & 1.55 & 0.217 \\
\hline & & & & & & Interaction & 0.31 & 0.575 \\
\hline
\end{tabular}

${ }^{a}$ Significant differences between periods, $\mathrm{p}<0.05$; ${ }^{\mathrm{b}}$ Significant differences between groups, $\mathrm{p}<0.05$; ST: Sedentary time; MPA: Moderate physical activity; VPA: Vigorous physical activity; MVPA: Moderate to vigorous physical activity.

\section{Discussion}

This study aimed to evaluate the effects of school-based physical activity intervention on behavioral and cardiometabolic risk factors in adolescents. We found that after 14 weeks of intervention, the IG showed lower values of total and daily ST, between groups and within periods. We also observed a reduction of glycemia levels between the pre- and post-periods.

We did not observe a significant increase of PA across different levels in the IG. An explanation for this is that an increase in the practice of PA leads to higher consumption of calories, an uncontrolled puzzling variable, making up for any energy expenditure that may have occurred ${ }^{34}$, or that the intensity of the exercises wasn't satisfactory. The principle of overload and compensation should be taken into account, since it is believed that in the 14-week period, there was no increase in the volume and intensity of PA, but rather an adaptation not followed by overcompensation. 
Table 3. Effect of the intervention on the outcomes' variables, adjusted by age and the age at PHV.

\begin{tabular}{|c|c|c|c|c|c|c|c|c|}
\hline & & \multicolumn{2}{|c|}{ IG } & \multicolumn{2}{|c|}{ CG } & \multirow[b]{2}{*}{ Effect } & \multirow[b]{2}{*}{$F$} & \multirow[b]{2}{*}{ p-value } \\
\hline & & Mean & SE & Mean & SE & & & \\
\hline & Pre- & 67.1 & 3.0 & 62.4 & 2.1 & Group & 1.01 & 0.316 \\
\hline \multirow[t]{3}{*}{ Weight (Kg) } & Post- & 65.4 & 2.8 & 62.3 & 2.1 & Time & 0.10 & 0.743 \\
\hline & & & & & & Interaction & 0.80 & 0.372 \\
\hline & Pre- & 20.3 & 1.7 & 17.8 & 1.2 & Group & 1.17 & 0.282 \\
\hline \multirow[t]{3}{*}{$\%$ FM } & Post- & 19.9 & 1.5 & 17,9 & 1,1 & Time & 0.13 & 0.718 \\
\hline & & & & & & Interaction & 0.13 & 0.716 \\
\hline & Pre- & $46.7^{\mathrm{a}}$ & 1.9 & 44.6 & 1.3 & Group & 0.38 & 0.539 \\
\hline \multirow[t]{3}{*}{ FFM } & Post- & $45.4^{\mathrm{a}}$ & 1.9 & 44.3 & 1.4 & Time & 0.00 & 0.971 \\
\hline & & $\mathrm{p}=0.030$ & & & & Interaction & 1.56 & 0.215 \\
\hline & Pre- & $153.5^{\mathrm{a}}$ & 4.1 & 157.8 & 2.9 & Group & 0.15 & 0.693 \\
\hline \multirow[t]{3}{*}{ Mean BP (mmHg) } & Post- & $163.7^{\mathrm{a}}$ & 3.4 & 155.9 & 2.4 & Time & 0.59 & 0.442 \\
\hline & & $\mathrm{p}=0.004$ & & & & Interaction & 0.01 & 0.096 \\
\hline & Pre- & $84.9^{\mathrm{a}}$ & 1.9 & 82.8 & 1.4 & Group & 0.05 & 0.818 \\
\hline \multirow[t]{3}{*}{ Glycemia (mg/dL) } & Post- & $83.0^{\mathrm{a}}$ & 1.6 & 86.0 & 1.2 & Time & 0.64 & 0.427 \\
\hline & & $\mathrm{p}=0.025$ & & & & Interaction & 3.82 & 0.055 \\
\hline & Pre- & 173.8 & 11.3 & 170.6 & 9.2 & Group & 0.21 & 0.663 \\
\hline \multirow[t]{3}{*}{ Total Cholesterol (mg/dL) } & Post- & 165.8 & 7.5 & 179.1 & 6.1 & Time & 0.16 & 0.696 \\
\hline & & & & & & Interaction & 1.09 & 0.327 \\
\hline & Pre- & 97.9 & 16.0 & $129.5^{\mathrm{a}}$ & 13.4 & Group & 1.04 & 0.325 \\
\hline \multirow[t]{2}{*}{ Triglycerides (mg/dL) } & Post- & 99.8 & 7.5 & $96.5^{\mathrm{a}}$ & 6.2 & Time & 2.58 & 0.129 \\
\hline & & & & $\mathrm{p}=0.017$ & & Interaction & 2.956 & 0.106 \\
\hline
\end{tabular}

*Values adjusted by age (16.66 years) and PHV (2.95 years). ${ }^{a}$ Differences between periods, $\mathrm{p}<0.05$; SE: Standard error; \%FM: Percentage of Fat mass; FFM: Fat-free mass; BP: Blood pressure.

Figure 3. Percentage of the Intervention Group (IG) and Control Group (CG) in the pre- and post-intervention moments according to the classification of the variables analyzed.

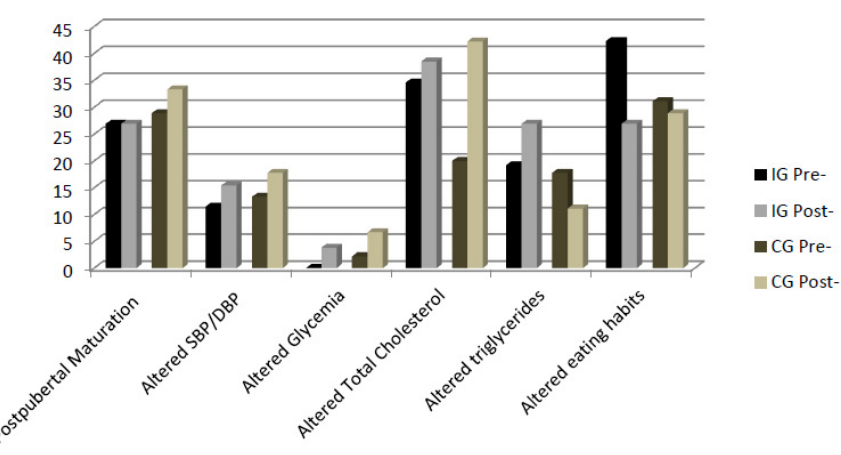

The American College of Sports Medicine ${ }^{35}$ holds a view on the amount of physical activity needed to achieve weight loss and prevent weight regain in adults. Findings on the relation of physical activity for weight loss and weight management in adolescents are inconsistent. There is some evidence that 150 250 minutes/week of moderate-intensity physical activity is associated with weight gain prevention. More than 150 minutes/ week of moderate-intensity physical activity is associated with modest weight loss, and greater amounts (i.e., > 250 minutes/ week) result in clinically significant weight loss. Additionally, there is some evidence that more than 250 minutes/week of moderate-intensity physical activity will prevent weight regain. Energy/diet restriction combined with physical activity results in higher weight loss than diet alone.

No positive changes in body composition were observed, corroborating results obtained by Leme, Lubans, Guerra, Dewar, Toassa, Philippi ${ }^{15}$, Harris, Kuramoto, Schulzer, Retallack ${ }^{36}$, Silveira, Taddei, Guerra, Nobre ${ }^{37}$, and Friedrich et al. ${ }^{38}$. A possible factor for this ineffectiveness may have been the duration of the intervention in this study. The period of time may have been too short for positive adaptation to occur in some of the parameters - other researchers have not found significant effects on body composition and behavioral variables in groups of adolescents after 12 months of physical activity sessions and nutrition workshop intervention ${ }^{39}$. However, more rigid control of the volume and intensity of the exercises in the intervention program could be a determining factor to have more significant modifications, even in a short period of time.

Given that all the adolescents were classified as pubertal or post-pubertal, they may have a larger percentage of body fat. Changes in the body composition of adolescents are markers of metabolic alterations that occur during pubertal development, especially among girls ${ }^{40}$. 
Another aspect to be taken into account is the fact that this intervention involved only monthly nutrition guidance combined with calorie expenditure through physical exercise, not strategies for actual changes in eating habits - unlike a school-based intervention study conducted by Feferbaum et al. ${ }^{12}$. With the presence of a team specialized in nutrition education, and meetings, lectures, cooking classes, practical classes, and recreational activities on healthy eating, there was a significant reduction observed in BMI and body proportions in the $\mathrm{IG}$, though no difference between the IG and CG. Additionally, according to a meta-analysis by Friedrich, Schuch, Wagner ${ }^{38}$, nutrition education and intervention should be considered in the planning of public policies in the health field, as they promote relevant results in the reduction of obesity in adolescence.

The results evince an elevated percentage of lipid abnormalities, as well as excessive sedentary time and bad eating habits, in both groups. Elevated prevalence of these health risk factors has also been reported in other studies with Brazilian adolescents $^{41-43}$.

We observed a reduction in total and daily ST, however there were no significant differences in the electronic aspect, corroborating a study by Dewar et al. ${ }^{39}$, which did not find significant differences in adolescents' screen time after 12 months of intervention. There was a significant difference between the IG and CG in the post-intervention period, showing that adolescents who participated in the intervention had less sedentary time than their CG peers.

The adolescents' eating habits in our study did not improve significantly. A systematic review by Kamath et al. ${ }^{44}$ shows that some studies did not obtain significant differences between the components of the intervention and the variables of sedentary time and eating habits, and a review by Sun et al. ${ }^{16}$ indicated that no significant differences were found between biochemical variables or blood pressure. Similar to our study, a 10 -week intervention study by Militão et al. ${ }^{13}$ did not find any significant differences between control and intervention groups in biochemical parameters or blood pressure. These findings lead us to discuss our intervention's short period of time and the control of puzzling variables such as the adolescents' daily eating habits.

Although there was no significant improvement in eating habits in the IG, we noticed a reduction in the group's total median score and in the percentage of adolescents with unhealthy eating habits in the altered classification for this variable, a factor that may explain the significant reduction in glycemia in the IG according to the ANCOVA analysis, since modifications in the diet are strongly associated with the reduction of glycemia, and high-fat hypercaloric diets can be associated with hyperlipidemia, hyperinsulinemia, and glucose intolerance ${ }^{45,46}$. In addition, the observed reduction of glycemic levels in the IG leads us to a study by Martelo ${ }^{11}$, which found that an aerobic intervention had satisfactory results, reducing some cardiovascular risk factors such as high glycemic levels. A study by Brand et al. ${ }^{20}$ states that the regular practice of physical activities combined with good nutrition promotes positive changes in glycemic levels and in other health risk factors.
Metcalf, Henley, Wilkin ${ }^{34}$ highlight that physical activity interventions have little effect on levels of global activity, which may partly explain why some interventions have limited results when it comes to BMI, body composition, and other health risk factors.

In addition, the short period of time of this school-based intervention program may be one of the reasons for the lack of effect on the adolescents' lipid and blood pressure variables, since positive adaptations in these parameters can take longer than 14 weeks due to the metabolic changes that occur during sexual maturation in this phase of life $\mathrm{e}^{40}$.

We believe there is a need for more involvement by parents/ legal guardians in intervention programs, to have more control over aspects that may get in the way of positive changes, such as adolescents having a TV in their bedroom and eating in front of screens ${ }^{25}$. A study by Nelson, Gordon-Larsen, Adair, Popkin ${ }^{47}$ showed that adolescents who have restrictions on screen time imposed by their parents tend to fulfill recommendations for physical activity, thus preventing the development of overweight/ obesity and other health risk factors. Along the same lines, Shang et al. ${ }^{48}$ demonstrated that there is a significant association between screen time and poor diets among adolescents.

The findings of this study reinforce the importance of programs and campaigns for changes in adolescent lifestyle. In addition, the results underscore the potential that school intervention has to reduce sedentary time and prevent longterm obesity.

Although the intervention was not effective in reducing health risk factors, such as body composition, lipid levels, and blood pressure, the school is considered an important environment to promote educational practices and motivate individuals to adopt healthy living habits and maintain them into adulthood.

Interventions performed at school and during leisure time bring health benefits. Regular physical activity is associated with skeletal health ${ }^{49}$, increased flexibility and aerobic capacity, and the reduction of risk factors for cardiovascular diseases ${ }^{20}$, especially when started in adolescence, because it prevents physical inactivity in adulthood ${ }^{50}$.

The main limitation of this study was the number of participants. The small sample reduced the study's ability in detecting effects of the intervention on the groups in the post-intervention period. Although the schools were randomly designated as IG and CG, the participants of the study were not randomized. In addition, the groups were unbalanced at baseline with respect to sedentary time, which could be a limitation in the analysis of this variable. Other limitations to be taken into consideration are the use of a subjective instrument to assess the level of physical activity and the short period of time in which the intervention was carried out.

Regarding biochemical variables, there was a reduction in the number of adolescents evaluated in each period (pre-intervention and post-intervention) for the cholesterol and triglyceride variables. The portable biochemical analyzer only shows values classified as "elevated" or close to this classification, while values below these levels are displayed as "normal," without giving numerical values for these variables. This bias should be considered when interpreting the results of the study. 
The main difficulties encountered throughout the process were the weak engagement of some adolescents in the program, which led to some sample losses, and a lack of trainees to help the researcher during intervention sessions. In spite of these limitations, this study is relevant. It was planned in a manner that makes it possible to implement the interventions in a school environment, and establishes eligibility criteria in the selection of a sample to avoid broad age ranges due to questions related to sexual maturation and growth ${ }^{51}$.

\section{Conclusion}

Our findings demonstrated that a 14-week intervention program involving controlled physical activity generated positive changes in glycemia and sedentary time, but not in body composition and physical activity level, which seems to indicate that the period of time was insufficient to bring about these kinds of changes. The significant reduction in sedentary time suggests that interventions involving the practice of physical exercise should be included and promoted in school environments, as physical activity is an important component of a healthy lifestyle.

We feel that the short duration of the intervention program may be one of the factors in the lack of effect on some of the cardiovascular risk factors evaluated in this study.

We suggest the implementation of interventions in schools, over a longer period of time, to analyze different adaptations and modifications of cardiovascular risk factors in adolescents, as well as to promote health and good living habits that ought to be followed from an early age. We also think that some aspects of school interventions, such as the improvement of eating habits, the increase of PA opportunities, and education about risk factors and heart-healthy behaviors, could be adopted into public policies.

\section{References}

1. World Health Organization. Global recommendations on physical activity for health. Geneva: WHO. 2010.

2. Ng M, Fleming T, Robinson M, Thomson B, Graetz N, Margono $\mathrm{C}$, et al. Global, regional, and national prevalence of overweight and obesity in children and adults during 1980-2013: a systematic analysis for the Global Burden of Disease Study 2013. Lancet. 2014;384:766-81.

3. Di Cesare M, Bentham J, Stevens GA, Zhou B, Danaei G, Lu Y, et al. Trends in adult body-mass index in 200 countries from 1975 to 2014: a pooled analysis of 1698 population-based measurement studies with 19.2 million participants. Lancet. 2016;387:1377-96.

4. Rivera J, de Cossío TG, Pedraza LS, Aburto TC, Sánchez TG, Martorell R. Childhood and adolescent overweight and obesity in Latin America: a systematic review. Lancet Diabetes Endocrinol. 2014;2:321-32.

5. Chaput JP, Lambert M, Mathieu ME, Tremblay MS, O'Loughlin J, Tremblay A. Physical activity vs. sedentary time: independent associations with adiposity in children. Pediatric Obesity. 2011;7:251-8.

6. Chaput JP, Saunders TJ, Mathieu ME, Henderson M, Tremblay MS, O'Loughlin J, et al. Combined associations between moderate to vigorous physical activity and sedentary behaviour with cardiometabolic risk factors in children. Appl Physiol Nutr Metab. 2013;38:477-83.

7. Albert MH, Drapeau V, Mathieu ME. Timing of moderate-tovigorous exercise and its impact on subsequent energy intake in young males. Physiol. Behav. 2015;151:557-62.

8. Gupta N, Goel K, Shah P, Misra A. Childhood obesity in developing countries: epidemiology, determinants, and prevention. Endocr Ver. 2012;33:48-70.

9. Guimarães Rf, Langer RD, Guerra-Junior G, Goncalves EM. Effectiveness of intervention programs in schools to reduce health risk factors in adolescents: a systematic review. Rev. bras. cineantropom. desempenho hum. 2015;17(4):485-495.

10. Farias ES, Paula F, Carvalho WRG, Gonçalves EM, Baldin AD, Guerra-Júnior G. Influence of programmed physical activity on body composition among adolescent students. J Pediatr (Rio J) 2009;85(1):28-34.

11. Martelo S. Effects of nutritional education associated with exercise on body composition and biochemical parameters in adolescents with excess weight. Nutrire: Rev. Soc. Bras. Alim. Nutr 2009;34(3):31-44.

12. Feferbaum R, Leone C, Nogueira RC, Cavalcanti PN, Cardoso EB, Serra MA. Avaliação antropométrica e por bioimpedância de um programa de educação nutricional para escolares na faixa etária de 7-14 anos durante o período de 10 meses. Rev Bras Crescimento Desenvolv Hum 2012;22(3):283-90.

13. Militao AG, Karnikowski MGO, da Silva FR, Militao ESG, Pereira RMS, Campbell CS. Effects of a recreational physical activity and healthy habits orientation program, using an illustrated diary, on the cardiovascular risk profile of overweight and obese schoolchildren: a pilot study in a public school in Brasilia, Federal District, Brazil. Diabetes Metab Syndr Obes 2013;6:445-51.

14. da Silva LS, Fisberg M, de Souza Pires MM, Nassar SM, Sottovia $\mathrm{CB}$. The effectiveness of a physical activity and nutrition education program in the prevention of overweight in schoolchildren in Criciuma, Brazil. Eur J Clin Nutr 2013;67(11):1200-4.

15. Leme AC, Lubans DR, Guerra PH, Dewar D, Toassa EC, Philippi ST. Preventing obesity among Brazilian adolescent girls: Six-month outcomes of the Healthy Habits, Healthy GirlsBrazil school-based randomized controlled trial. Prev Med. 2016;86:77-83.

16. Sun C, Pezic A, Tikellis G, Ponsonby AL, Wake M, Carlin JB, et al. Effects of school-based interventions for direct delivery of physical activity on fitness and cardiometabolic markers in children and adolescents: a systematic review of randomized controlled trials. Obes Rev. 2013;14:818-38.

17. Tremblay MS, LeBlanc AG, Kho ME, Saunders TJ, Larouche R, Colley RC, et al. Systematic review of sedentary behaviour and health indicators in school-aged children and youth. Int J Behav Nutr Phys Act. 2011;8:98. 
18. Telama R, Yang X, Viikari J, Välimäki I, Wanne O, Raitakari O. Physical activity from childhood to adulthood: a 21-year tracking study. Am J Prev Med 2005;28:267-273.

19. Olsen NJ, Mortensen EL, Heitmann BL. Predisposition to Obesity: Should We Target Those Most Susceptible? Curr Obes Rep. 2012;1:35-41.

20. Brand T, Pischke CR, Steenbock B, Schoenbach J, Poettgen $\mathrm{S}$, Samkange-Zeeb F, et al. What works in communitybased interventions promoting physical activity and healthy eating? A review of reviews. Int J Environ Res Public Health. 2014;11:5866-88.

21. Schulz KF, Altman DG, Moher D, for the CONSORT Group. CONSORT 2010 Statement: updated guidelines for reporting parallel group randomised trials. BMJ 2010;340:c332.

22. Mirwald RL, Baxter-Jones AD, Bailey DA, Beunen GP. An assessment of maturity from anthropometric measurements. Med Sci Sports Exerc. 2002;34(4):689-94.

23. Guedes DP, Lopes CC, Guedes JERP. Reprodutibilidade e validade do Questionário Internacional de Atividade Física em adolescentes. Rev Bras Med Esporte. 2005;11:151-8.

24. Guimarães RF, Silva MP, Legnani E, Mazzardo O, Campos W. Reproducibility of adolescent sedentary activity questionnaire (ASAQ) in Brazilian adolescents. Rev Bras Cineantropom Desempenho Hum. 2013;15:276-85.

25. American Academy of Pediatrics: Children, adolescents, and television. Pediatrics 2001;107:423-6.

26. Stewart A, Marfell-Jones M, Olds T, Ridder H. International standards for anthropometric assessment (ISAK). Lower Hutt, New Zealand, 2011.

27. Cole TJ, Lobstein T. Extended international (IOTF) body mass index cut-offs for thinness, overweight and obesity. Pediatr Obes. 2012;7(4):284-94.

28. Kyle UG, Bosaeus I, De Lorenzo AD, Deurenbergd P, Eliae M, Gomez JM, et al. Bioelectrical impedance analysis--part I: review of principles and methods. Clin Nutr. 2004;23:1226-43.

29. Houtkooper LB, Going SB, Lohman TG, Roche AF, Van Loan M. Bioelectrical impedance estimation of fat-free body mass in children and youth: A cross-validation study. J Appl Physiol. 1992;72:366-73.

30. Chiara VL, Sichieri R. Food consumption of adolescents. A simplified questionnaire for evaluating cardiovascular risk. Arq Bras Cardiol. 2001;77:332-41.

31. I Diretriz Brasileira de Diagnóstico e Tratamento da Síndrome Metabólica. Arq Bras Cardiol. 2005;84:3-28.

32. Bloomgarden ZT. American Diabetes Association 60th Scientific Sessions, 2000: glucose tolerance, diabetes and cancer, glycemic control, monitoring, and related topics. Diabetes Care. 2001;24:779-84.

33. The Fourth Report on the Diagnosis, Evaluation, and Treatment of High Blood Pressure in Children and Adolescents. Pediatrics. 2004;114:555-76.

34. Metcalf B, Henley W, Wilkin T. Effectiveness of intervention on physical activity of children: systematic review and metaanalysis of controlled trials with objectively measured outcomes (EarlyBird 54). BMJ. 2012;345:e5888.

35. Donnelly JE, Blair SN, Jakicic JM, Manore MM, Rankin JW, Smith BK. American College of Sports Medicine. Position Stand.
Appropriate Physical Activity Intervention Strategies for Weight Loss and Prevention of Weight Regain for Adults. Med Sci Sports Exerc. 2009 Jul;41(7):1532.

36. Harris KC, Kuramoto LK, Schulzer M, Retallack JE. Effect of school-based physical activity interventions on body mass index in children: a meta-analysis. CMAJ. 2009;180(7):719-26.

37. Silveira JA, Taddei JA, Guerra PH, Nobre MRC. Effectiveness of school-based nutrition education interventions to prevent and reduce excessive weight gain in children and adolescents: a systematic review. J Pediatr (Rio J). 2011;87:382-92.

38. Friedrich RR, Schuch I, Wagner MB. Efeito de intervenções sobre o índice de massa corporal em escolares. Rev Saúde Pública. 2012;46:551-60.

39. Dewar DL, Morgan PJ, Plotnikoff RC, Okely AD, Collins CE, Batterham M, et al. The nutrition and enjoyable activity for teen girls study: a cluster randomized controlled trial. Am J Prev Med. 2013;45:313-7.

40. Barbosa KBF, Franceschini SCC, Priore SE. Influência dos estágios de maturação sexual no estado nutricional, antropometria e composição corporal de adolescentes. Rev Bras Saúde Mater Infant. 2006;6:375-82.

41. de Moraes AC, Musso C, Graffigna MN, Soutelo J, Migliano M, Carvalho HB, et al. Prevalence of cardiovascular risk factors among Latin American adolescents: a multilevel analysis. J Hum Hypertens. 2014;28(3):206-9.

42. Stabelini Neto A, Santos GC, Sena JS, Correa RC, Elias RGM, Campos W. Atividade física e fatores associados à prevalência de síndrome metabólica em adolescentes. Revista da Educação Física / UEM. 2014;25:619-28.

43. Kuschnir MC, Bloch KV, Szklo M, Klein CH, Barufaldi LA, Abreu GA, et al. ERICA: prevalence of metabolic syndrome in Brazilian adolescents. Rev Saúde Pública. 2016;50 Suppl 1.

44. Kamath CC, Vickers KS, Ehrlich A, McGovern L, Johnson J, Singhal V, et al. Behavioral Interventions to Prevent Childhood Obesity: A Systematic Review and Metaanalyses of Randomized Trials. J Clin Endocrinol Metab. 2008;93:4606-15.

45. Sociedade Brasileira de Cardiologia. I Diretriz de Prevenção da Aterosclerose na Infância e na Adolescência. Arq Bras Cardiol. 2005;85:3-36.

46. Bloomgarden ZT. American Diabetes Association 60th Scientific Sessions, 2000. Glucose tolerance, diabetes and cancer, glycemic control, monitoring, and related topics. Diabetes Care. 2001;24(4):779-84.

47. Nelson MC, Gordon-Larsen P, Adair LS, Popkin BM. Adolescent physical activity and sedentary behavior: patterning and long-term maintenance. Am J Prev Med. 2005;28:259-66.

48. Shang L, Wang J, O'Loughlin J, Tremblay A, Mathieu ME, Henderson M, et al. Screen time is associated with dietary intake in overweight Canadian children. Prev Med Rep. 2015;2:265-9.

49. Linden C, Ahlborg HG, Besjakov J, Gardsell P, Karlsson MK. A school curriculum-based exercise program increases bone mineral accrual and bone size in prepubertal girls: two-year data from the pediatric osteoporosis prevention (POP) study. J Bone Miner Res. 2006;21(6):829-35.

50. Carrel AL, Clark RR, Peterson SE, Nemeth BA, Sullivan J, Allen DB. Improvement of fitness, body composition, and insulin sensitivity in overweight children in a school-based exercise 
program: a randomized, controlled study. Arch Pediatr Adolesc Med. 2005;159(10):963-8.

51. Guerra PH, Nobre MR, da Silveira JA, Taddei JAAC. Schoolbased physical activity and nutritional education interventions on body mass index: a meta-analysis of randomised community trials - project PANE. Prev Med. 2014;61:81-9.

\section{Acknowledgements}

This study had the support of Faculdade de Ciências Médicas (School of Medical Sciences) of UNICAMP, of Laboratório de Crescimento e Desenvolvimento and of Centro Universitário Salesiano de São Paulo - UNISAL Liceu Salesiano. The authors thank the Coordenação de Aperfeiçoamento de Pessoal de Nível Superior (CAPES) and the National Counsel of Technological and Scientific Development (CNPq process no.: 462310/2014-0) for the financial support, and UNISAL for providing the space for the performance of the interventions.

\section{Corresponding author}

*Roseane de Fátima Guimarães.

UNISAL. Rua Baronesa Geraldo de Resende, 330, Guanabara, Campinas - SP, 13075-270, Campinas, SP, Brazil.

Email: roseanefguimaraes@gmail.com

Manuscript received on June 2, 2017

Manuscript accepted on August 6, 2017

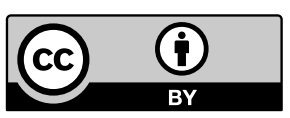

Motriz. The Journal of Physical Education. UNESP. Rio Claro, SP, Brazil - eISSN: 1980-6574 - under a license Creative Commons - Version 3.0 